small meeting to pledge the Association to a decision upon that point. He suggested that the resolntion should be couched in more general terms.

Dr. BuCKNILC asked whether the medical officers would like to be placed nnder the Local Government Board, or any such department. He had no doubt that, on the whole, the pensions granted by the Visiting Justices were in excese of those given under the statatory olaim of their brethren in Ireland.

In reply, Dr. LiNDsay stated that he had as high an opinion of the Visiting Justices of County Asylums as Dr. Bucknill, and he had never hesitated to express that high opinion; but he had not the same faith in the Quarter Bessions, becanse the Justices there did not know all the circumstanoes; they were liable to be unfarourably influenced, and were not always able to take such a just view of the matters in question, as those justices who, being members of the Visiting Commitrees of the asylums, were thoroughly acquainted with the officers. Moreover, changes were inevitable, involving the transfer of the asylums to County Boards, or, perhaps, to the Local Government Board.

$\Delta$ fter some further discussion as to the resolution,

Dr. LiNDSAY said that, acting on the suggestion of the President, he should amend his proposition, so as to make it more general. He therefore begged leare to move-" That in the opinion of this meeting, granting pensions to the officers and staff of County and Borough Lunatic Asylums should be no longer permiseive, but compulsory."

The resolution having been seconded by Dr. BkUsHpirLd, was carried.

BRITISH MEDICAL ASSOCIATION.-ANNUAL MEETING, CORK, 1879.

Section or Psychologr.

\title{
Discussion on the Prevention of Insanity."
}

The discussion was arranged under the following heads :-(a), Ascertaining and classification of causes; (b), the legitimate prevention of hereditary trans. mission; (c), the influence of bad sanitary conditions; (d), the effeot of the teaching of elementary physiological principles; and was opened by $\mathrm{Dr}$. HerBert C. MAJOR, who arged that the importance of the subject could not be over-estimated. While increase in the proportion of persons becoming insane was still open to some doubt, there could be no doubt of the annual growth of the insane population from the accumulation of incurable cases ; and if such accumulation was to be checked, it was to be done by preventing, by every possible means, the occurrence of fresh cases. It was not sufficient, when insanity had once supervened, to insist on early treatment. This, although most advisable, would in many cases fail to bring about a cure, with our present knowledge, from the fact that of tentimes there existed with the onset of mental symptoms grave or incurable cerebral lesions. Taking up specially the question of the ascertaining and classification of causes of insanity $\rightarrow$ subject which must form the starting point for all efforts at prevention-the importance in the first place of the adoption of a satisfactory scientific system of classification was alluded to, as also the ntter inadequacy of the system adopted in most asylum reports. While the difficulties and uncertainties attending the forming of a correct idea of the cause inducing insanity in our cases were often very great, this was no argument against continued

- For this report we are indebted to M.S. placed at our disposal by the British Medical Journal. 
patient investigation. But the value of results thus obtained would depend very much upon the adequate expression in statistical tables. It was therefore greatly to be desired that without loss of time a system of tabulation should be devised which might fairly meet the requirements of the case. Further, that such a method having been recommended by competent authorities, should be adopted in all asylums, not in this country only, but also in our Colonies; and thirdly, that the results thus elicited should be made known for the guidance of medical men and (through them mainly) of the community. The tables of the English Commissioners in Lunacy were doubtless a valuable step in this direction, but more remained to be done; and it was for asylum physicians, by their individual efforts, to render such statistics of still greater public utility and benefit.

(A Paper by Dr. Rabagliati was read by Dr. Major in the absence of the writer.)

The first part, which referred to the classification of causes of insanity, was not read for want of time. In the second part-dealing with heads (b), The legitimate prevention of hereditary transmission; $(c)$, the influence of bad sanitary conditions; $(d)$, the effect of the teaching of elementary physiological principles-Dr. Rabagliati spoke of the present deplorable state of the country, where one in every 25 or 30 of the popalation is a pauper, and stated that in Yorkshire alone there were 2,900 pauper lunatics in the county asylums, besides thuse in the workhouses. He considered that the ratepayers would be quite justified in insisting on a forcible limitation of such a state of things, and suggested that in the present ignorant state of the mass of society, marriage should be prohibited with persons who had ever been insane and at any period of adult life chargeable on the rates. He even thought there ought to be no objection offered to apply such a provision to all insane persons whatever, on the ground that the individual liberty should never endanger the common good. Nevertheless, he felt that compulsory legislation was to be deprecated where people were sufficiently educated to be convinced by moral persuasion and argument, and thought it was very desirable that public opinion should be educated by a fair and truthful statement of the facts regarding the progeny of diseased persons. His own opinion, based on a careful examination of facts collected in the out.patient room of the Infirmary, was that insanity is only one group of a large class of closely allied diseases, such as scrofula, consumption, cancer, and perhaps syphilis. It might seem unreasonable to interfere forcibly with the marriage of persons affected by any of these diseases, but there is already generally a strong feeling against such marriages, and much might be done by education to develop and strengthen such a feeling. $\mathrm{He}$ thought, however, that there was an aspect of this question which was often overlooked - that even the children of unhealthy parents might be brought up in good sanitary conditions, with well-selected food, properly arranged work, sleep, exercise in the open air, in a saitable climate, and so develop a more healthy constitation than that which they inherited. Doctors were apt to forget that the race may thus be developed upwards as well as downwards, because, though they are constantly consulted in the cases of unhealthy children, when unhealthy parents have children who turn out healthy, medical aid is not required, and therefore such cases do not come under their notice. He thought it quite possible that by skill, judgment, and constant care, the delicate children of unbealthy parents might be developed into healthy adults just as readily as unhealthy children, through ignorance and neglect, are constantly developing these very diseases. Care in bringing up children was the chief agent in making bealthy men and women, and he thought it, therefore, most necessary that the principles of sanitary science, of feeding, clothing, exercising, working, and resting children, and their various powers and requirements, should be taught in the higher Board Schools, as also the responsibilities and capacities of parents. This, which would benefit the whole country, 
might well be done at the country's cost. In order, however, to give such care to their children, parents must have the neans to do so, and with very large families this would generally be impossible. He felt this to be a most delicate part of the subject, but its importance made it necessary to speak plainly. It was far too common to hear of large families of whom nearly or mure than half died in infancy. Among the lower classes especially this was generally the case. Such instances often came before him every day. Half the children born in the conntry die before the age of five years. This system was, to say the least of it, a wastefal one, even from a pecuniary point of view, and considering the negleot of even the surviving children from want of means and time on the part of the parents, and the too frequent ill-health and premature death of the over-wrought mother, its consequences were most sad. He thought that in our over-peopled country the number of children in a family should average three, who conld then be properly cared for; but were the present high death-rate to continue, then the average number should be five or six. He had heard it objected that such a conrse would only be followed by the pradent and thoughtful, who would then soon be swamped by the idle and profligate still multiplying without check; but this was a shallow argument, and overlooked the lessons of history and the influence on the masses of sach men as Wesley or Cromwell, or the ten who would have saved Sodom. Were he asked how he would effect this limitation of families, he would reply in the words of him who said, "The time is short; it remaineth that they that have wives be as though they had none." Abstinence should be adrocated to bring about this desirable result; no other measures could command respect from rightly disposed and high-minded persons.

Mr. Mould-One cannot but feel that to attempt to deal with passion, feeling, and emotion is one of the mort difficult problems we have before us. It is simply impossible to attempt to interfere with the individual liberty of the subject in these matters ; it is generally a matter of feeling, and rarely of judgment. People marry not because they have found, after careful enquiry and due consideration, that they are perfectly healthy, but from other and more emotional considerations; and I feel assured that it is both injudicious and inexpedient for scientific men to interfere with the relations between the sexes, and especially the regulation of the number of children. In the prevention of insanity there can be no doubt that very much can be done to assist the heslthy growth of children both in the middle and lower classes-in the former with suitable food, in the latter with both suitsble and sufficient food and healthy surroundings. In this manner, by assisting the healthy growth of the body, we so assist the healthy growth of the mind; and it has often been a sonrce of astonishment to me that some means should not be taken by those in anthority to feed as well as to educate children, especially those of tender years. I have been very much struck since I have been in Cork with the healthy appearance of all the children I have seen (and they appear very nnmerons), and I wonld attribnte it to a full and sufficient freedom they seem to have from the confinement of the immediate neighbourhood of their small and of necessity frequently unsavoury dwellings, and one would wish that in our large manufacturing counties greater attention should be paid to the forcible observance of the plain, simple, and natural laws of health, more especially in bealthy life. Unfortunately in asylum practice we have but little to do with the prevention of insanity-our efforts are more directed to its cure-and that generally in the acute or advanced stages; but we can treat, especially in our medical schools, what we know to be so essentially necessary to the bealthy condition of mind of those who, either from hereditary transmission or from unfortunately acquired causes, are peculiarly liable to mental disease.

Dr. AsH - I think some fallacy must underlie the Malthusian doctrine supported by Dr. Rabagliati. The strength of the sexual instinct seems to me to prove that the intentions of the Creator on the subject are unmistakeable, and 
not to be set aside without serious consequences resulting. In accordance with the doctrine of natural selection, a great superabundance of life is required, from which the individuals most fit for survival are selected. The compulsory separation of hasband and wife, suggested by Dr. Rabagliati, could only result in one of two things; either the substitution of irregular and illicit relations between the sexes for those which are regular and lawfal, or else in other and atill more serious deviations from the design of Nature, having a still greater tendency to fill our asylums. I think that with a view to the prevention of insanity it will be necessary by further research to correlate insanity with other abnormal or diseased conditions, and after having thus arrived at a truly scientific classification of insanity, to base a sound therapentic system thereon, and, having done so, to spread this scientific knowledge of the disease amongst general practitioners, so that the earlier stages may be brought under a sound and rational system of treatment.

Dr. Bodington-It will be agreed on all hands that one chief means of the prevention of insanity is to diffuse a knowledge of mental physiology amongst the public. The ignorance on all questions concerning the mind is great and wide-spread. It is impossible under present conditions to get people to entertain the view that the phenomena known as mind are dependent on brain function, and should come under treatment upon the ordinary principles of medicine. They persist in speaking and thinking of "the mind" as an entity quite distinct and apart from the body, to be dealt with on different grounds and by other methods. Again, there is a consensus of opinion amongst us that lunacy should be regularly tanght in all medical schools as a branch of medicine. This is desirable, not only for the sake of lunacy practice, but aiso that medical men, coming as they do into the most intimate contact and relation with families, may be competent to influence them to take what precantions are necessary for the forestalling and prevention of attacks. With that object in view, it might be desirable for lunacy practitioners, through the medium of the Medico-Psychological Association, to suggest to the authorities of medical schools that they should at once make lunacy a part and parcel of the ordinary conrse of instruction in medicine. The diploma and degree granting bodies seem little likely to make it compulsory, but the schools might, if they chose, exact a course of lectures and clinical instruction in insanity from all their students. I perfectly concur with all Mr Mould said regarding the value of good food, but, of course, it should be remembered that insanity occurs among all classes of society where food is as substantial and abundant as can be, and hence other causes must be looked for. Amongst these, over-forcing of young brains must be reckoned; it is one, I think, very rife just now, and it has led to many unhappy consequences. Cases of suicide occur, to my mind, as distinctly traceable to this canse. I am told by an Oxford Fellow and tator that one or two cases of suicide by nndergraduates assuredly occur yearly in that University, and in his opinion they are mostly due to the fatigue, anxiety, and distı ess arising from excessive brain-work, and undue competition struggles. A year or two since I had a Cambridge undergraduate under my care, suffering from mania, distinctly traceable to overwork, wanton sacrifice of sleep, and anxiety about examinations as the exciting cause. Instances of premature breakdown of mental capacity, as well as of the general health, occur to me. Parents send little boys to preparatory schools, and insist on having them finely ground and polished in classics and mathematics, without reference to their capabilities, so that they may make a figure on the public schools. I have it on the testimony of the master of a large preparatory school, that boys thas forced hreak down frequently at 15 and 16 , and do nothing more thereafter. He tells me that it is a pain and grief to him to be teaching Latin verses and Homer to little boys of 13, obviously nnequal to the task. He is, however, helpless; the great public schools still demand these things, and parents unwisely insist on them. On the other hand, I am acquainted with a public school-Giggleswick School, in Yorkshire, where science and modern languages hold a prominent place. The 
first science taught is botany, after that, chemistry, and, subsequently, experimental physics. I am assured, on good testimony, that the teaching of botany to little boys is found to be most valuable in helping along the dull ones in their school career. It cultivates, of course, their powers of observation, but it also excites their interest and relieves the tedium of the dreary round of classics and mathematics, and promotes industry and happiness. I cannot helpthinking that one of our greatest means for the prevention of insanity is healthy educetion. While I quite concur in all that has been said with regard to food and hygiene, we must, by no means, neglect the early training of the mind, which, in my view at the present moment, is, in too many instances, unwise, injurious, and even barbarons. As physicians treating insanity, and desiring to do all we can to prevent it, it is, I think, our bounden daty to set our faces against the brain-forcing, now so common, and generally to endeavour to get the education of the young established on a sound footing, and conducted by healthy methods.

Dr. Murray Lindsay - Dr. Major has directed our attention to a very important and, at the same time, very difficult subject, the prevention of insanity. Those engaged in asylum practice have chiefly to deal with the cure of insanity, but prevention of disease is even more important than its cure, and our best effort should be also directed towards aiding in any measure that will tend to the prevention of insanity. I must endorse the able and practical observations of Dr. Major as to a more satisfactory classification of the canses of insanity and greater uniformity in the statistical tables of asylum reports. It is very desirable that psychologists should be able to instruct medical practitioners, but, before being in a position to do so, we must first arrive at a better understanding amongst ourselves as to some standard and greater uniformity of statistical tables. With regard to such tables, the result of my experience is that the causation of insanity is generally compound, several canses frequently operating in producing mental disorder. The same holds good with regard to the causes of death in those dying in asylums. In filling up such tables it is desirable to put down all the causes operating to produce insanity in each case, as well as the canses operating in producing death in each individual case. In order to obtain greater accuracy and nniformity in this respect, it is incumbent on asylum medical officers to do their best to obtain as careful and accurate histories as possible of the cases admitted, and to ascertain the causes of death in as many cases as possible by post mortem examinations, which appear to be neglected, or for some reason, not carried out in some asylums. In conclusion, I would say that with regard to the prevention of insanity medical officers of health should be able to render very valuable aid in this direction.

Dr. OsCar Woods-I acknowledge the great benefit to be derived from a careful classification of the causes of insanity, and regret that it is impossible to classify the causes very accurately in the Irish asylums, owing to the want of information in the committal forms, few facts being stated, and the medical man, as a rule, certifying on hearsay, not on facts observed by himself. Friends rarely accompany patients to the asylums, they are bronght in obarge of the police, who know nothing of their history. I hope that when the report of the Commissioners, lately laid before the House of Commons, is being considered, the committal forms for dangerous lunatics will be done away with, and a form similar to that in use in England be adopted instead. Mnch good might also be derived from the tables recommended by the Medico.Psychological Association being generally used in Irish asylums.

Dr. Ringrose ATKIns-It is acknowledged on all hands that, like other diseases, to which the human organism is heir, the canses of insanity must be definitely ascertained-those varions and diverse influences, be they simple or multiple, which lead up to or bring about the mental alienation-before any steps can be taken to sucossfully combat their attacks or reduce their infla. ences for evil; and it is in this ascertainment of causes on the very threshold of the enquiry, as it were, that we Irish asylum physicians are met by difficul- 
ties which, it seems in the present condition of things, almost impossible to overcome; diffionlties due to the insufficient or absolute absence of information as to what the attack in any individual case or cases may be ascribed to This state of things outside the asylum the physician himself appears to defend upon two conditions; on the one hand, the comprative ignorance or want of aptitude on the part of the certifying medical practitioner who, in his student career, had learned as regards the subject of insanity little more, if even so much, as the meaning of certain terms which be subsequently uses most loosely or perhaps improperly, while he is quite nnacquaintad with the investigation of those intricate factors which are at work in the production of the cerebro-mental disorder. and on the other hand, to the unthinking and often wilful concealment of all important facts and information on the part of the friends of those afflicted. The prelude, then, to the prevention of insanity should be the dissemination of a knowledge of insanity during their student careers, amongst those who may be afterwards called upon to cope with the disease in its incipient manifestations, or to give advice which, if judicions, may prevent an attack, as well as teaching the public generally the nature of brain structure and brain function in health, and leading them to see in mental derangement, actual disease of organic stmctures, and not merely mental alterations which should be concealed as much as possible, as being outside the true domain of medical science, and indicative of Divine wrath and displeasure. They will then realise the delicacy of those nervous structures, know how to conserve their functions, and when derangement does ensue, be able and willing to give such information as may aid the phrsician in his search for the cause, which may, in many cases, be but of a temporary or removable character. I entireiy concur with the remarks which have fallen from Mr. Mould; if the young brain is to ripen and develop to maturity, it must have pabulnm from whence to draw that nutriment on which the developmental processes depend, and it must be surrounded by such influences as will allow these developmental processes to have free play and power in its growth; however, it must not be worried or forced ; if it is, its functions may indeed appear to bloom when they should be but budding, but they will fade before full fruition comes; too early development must pay the penalty of premature decay. I entirely agree with Dr. Bodington in his condemnation of the system of education now pursued in many schools and educational establishments. I think we mnst all regard the practice of teaching so largely by pare efforts of memory as most baneful in its effects. I would gladly see introduced the system of teaching by demonstration, of appealing to the intellect throngh the senses; and the information thus gained would, I believe, be far more permanent, far more interesting to the student, and far less injurions to the delicate organisation of the brain. If insanity can be prevented, if it is possible to lessen the ravages of mental derangement, we must begin by 80 building the brain-the organ of the mind

- that when the wear and tear of after-life comes, its structures, nourished and bealthy, may be able to stand the shocks to which it may be sabjected while passing through the shoals and quicksands of life.

Dr. MaJOR replied on the part of Dr. Rabagliati to some of the criticisms made on his views regarding the limitation of the number of children, after which the discussion terminated.

The following papers were read and discussed :-

The Psycho-physiological Training of an Idiot Hand. By E. Seguin, M.D. Now York).

On Claustrophobia. By B. Ball, M.D. (Paris).

Metalloscopy in the Treatment of Hysterical Hemianasthesia. By Ringrose Atkins, M.D. (Waterford).

On the Prevention of Suicide. By W. F. Wade, F.R.C.P. (Birmingham).

Intemperance in Study. By D. Hack Tuke, M.D. (London).

Csteomalacia amongst the Insane. By Ringrose Atkins, M.D. (Waterford). 